\title{
NOTAS SOBRE O SE REFLEXIVO NO DIALETO DO PB FALADO EM ALAGOAS
}

\author{
Dorothy Bezerra Silva de Brito \\ Universidade Federal de Alagoas
}

Resumo: Este artigo apresenta uma discussão sobre a anáfora reflexiva se no dialeto do Português Brasileiro falado em Alagoas. Através de uma revisão da proposta de análise de Menuzzi (1999, 2004) para dependências anafóricas em que a forma pronominal a gente é o antecedente, questiono que tipo de concordância entra em jogo quando a anáfora $s e$, como nos contextos analisados, pode ter qualquer pronome sujeito como antecedente.

Palavras-chave: SE reflexivo; anáfora; localidade; concordância

\section{Introdução}

Este artigo propõe a discussão das exigências sintáticosemânticas requeridas em dependências anafóricas em que a anáfora reflexiva se é a forma dependente. Como ponto de partida, observemos a sentença abaixo, que é gramatical no dialeto do Português Brasileiro (doravante PB) falado em Alagoas:

(1) Eu se acordo cedo todos os dias.

Retomando as noções básicas da teoria da ligação segundo a qual uma anáfora deve ter um antecedente, isto é, um elemento de mesmo índice; e que este antecedente deve c-comandar a anáfora, vemos que a relação de c-comando é estabelecida, mas a co-indexação entre os elementos não é possível, uma vez que eu e se não possuem a mesma especificação gramatical. Ainda assim, não há dúvida de que é

Este artigo representa parte da reflexão que fará parte de tese de doutorado (em andamento) sob orientação da Profa. Dra. Maria Denilda Moura. Dorothy Bezerra Silva de Brito é doutoranda em Lingüística pela Universidade Federal de Alagoas e bolsista da Fundação de Amparo à Pesquisa de Alagoas (FAPEAL). 
ao pronome $e u$ que o se refere. A questão que se impõe é qual o tipo de concordância que deve existir entre as formas associadas.

\section{A análise de Menuzzi $(1999,2004)$}

Menuzzi (2004) já discute os contrastes de concordância entre forma anafórica e antecedente, mas em contextos como ilustrados abaixo:

(2) a. A gente $_{\mathrm{i}}$ já $\left\{s e_{\mathrm{i}} /\right.$ *nos $\left._{\mathrm{i}}\right\}$ viu na TV

b. A gente $e_{\mathrm{i}}$ soube que o Paulo nos $_{\mathrm{i}}$ viu no Giovannetti ontem

Como a questão que levantamos é similar à que Menuzzi discute, uma revisão da sua proposta de análise pode ser útil também para esclarecer a possibilidade de o se ter qualquer pronome pessoal como antecedente.

Menuzzi (op.cit.) inicia o seu artigo questionando a distinção entre condições "puramente gramaticais" (que fazem referência somente a conceitos sintáticos, como relações estruturais - regência, ccomando, irmandade etc. - categorização sintática - NP, VP etc. especificação de traços formais - Caso, gênero e número em adjetivos etc.) e condições "semânticas" (que são impostas às expressões lingüísticas em função do seu significado - papéis temáticos e os índices referenciais, por exemplo). Ele também mostra que, a depender de quais condições sejam priorizadas, o modelo de gramática que se estabelece é afetado, o que o faz concluir que "um estudo sistemático dos 'conflitos' entre condições gramaticais e semânticas pode revelar muito da estrutura da gramática - em particular, pode indicar se o modo de interação entre 'gramática' estrito senso e semântica envolve uma relação direcional, ou se exige uma relação não-direcional, de "computação paralela"' (2004, p. 99-100).

O autor parte da observação de que, normalmente, não atribuímos interpretações que não sejam apropriadas a um NP. Ele exemplifica com as frases abaixo, que seriam inaceitáveis caso fossem atribuídos aos NPs em itálico os referentes representados pelos índices fornecidos:

a. *João $o_{\mathrm{i}}$ chegou tarde. $\mathrm{i}=[$ Paulo $]$

b. João $o_{\mathrm{k}}$ chegou tarde. *Ela ${ }_{\mathrm{k}}$ estava atrasada. $\mathrm{k}=$ [João] 
Ele afirma então existir uma condição geral que rege as relações entre sintaxe e semântica segundo a qual NPs devem receber uma interpretação compatível com o seu significado lexical, que ele nomeia COMPATIBILIDADE SEMÂNTICA (COMPSEM):

COMPATIBILIDADE SEMÂNTICA [COMPSEM]:

Um índice deve ser compatível com as especificações lexicais do NP ao qual é atribuído.

Menuzzi afirma que a interação de COMPSEM com condições "gramaticais" pode explicar alguns problemas de concordância entre forma anafórica e antecedente. Uma importante observação é a possibilidade de violação de COMPSEM, de acordo com efeitos de sentido que se deseje produzir (por exemplo, a frase (b) que, segundo o autor, pode representar "uma ironia fácil de detectar"(p.100).

A partir dessas formulações, Menuzzi inicia a análise de diferentes dependências anafóricas, entre as quais nos interessa mais imediatamente aquelas onde a expressão a gente é o antecedente. Mesmo sendo gramaticalmente especificada como forma de $3^{\mathrm{a}}$ pessoa, a gente pode ser interpretada como se referindo à $1^{a}$ pessoa do plural, o que possibilita o seu uso em relações anafóricas com outras formas pronominais (um clítico, no exemplo abaixo) de $1^{\mathrm{a}}$ pessoa do plural (1 ppl), como em (2b), repetido em (3):

(3) A gente $_{\mathrm{i}}$ soube que o Paulo nos $\mathrm{i}_{\mathrm{i}}$ viu no Giovannetti ontem.

$$
[i=1 \mathrm{ppl}]
$$

Menuzzi observa que o modo de descrever o uso da expressão $a$ gente como forma de $1 \mathrm{ppl}$ constitui uma violação de COMPSEM, já que a gente é especificada como $3^{\mathrm{a}}$ pessoa do singular e não pode ser compatível com o índice referencial de $1^{a}$ pessoa do plural. Embora COMPSEM seja violada, essa violação não leva a inaceitabilidade das frases, o que o faz admitir que esta seja uma violação tolerada de COMPSEM. Em contrapartida, o contraste abaixo evidencia que a relação anafórica entre a gente e os pronomes de $1 \mathrm{ppl}$ só é permitida quando o contexto não é "local"”, ou seja, quando há alguma

Menuzzi chama de "local" a relação anaforica entre um NP na posição de sujeito e outro na posição de objeto direto, que formam uma configuração sem qualquer barreira, seja qual for a teoria da localidade ou a 
"distância sintática" envolvida (como em (3)); de outro modo, é o reflexivo de $3^{\mathrm{a}}$ pessoa que é aceitável como forma anafórica para $a$ gente, como ilustra (2a), repetido abaixo:

(4) A gente $e_{\mathrm{i}}$ já $\left\{\right.$ se $_{\mathrm{i}} /{ }^{*}$ nos $\left._{\mathrm{i}}\right\}$ viu na TV

Com base no acima exposto, é proposta uma análise baseada na hipótese de Reinhart \& Reuland (1991, 1993), segundo a qual relações anafóricas "locais" contam como "cadeias" de movimento e estão, portanto, sujeitas a condições sobre cadeias. Menuzzi (1999) sugere a modificação desta hipótese para que as relações anafóricas não sejam consideradas "cadeias primitivas", mas "cadeias por analogia". Nessa acepção, as condições sobre cadeia não atuariam de modo absoluto sobre relações anafóricas, podendo ser violadas proporcionalmente ao grau de similaridade entre a relação anafórica e o "formato" de uma cadeia: quanto mais a relação anafórica parecer uma cadeia, mais fortes serão os efeitos que mostrarão as condições sobre cadeia.

A condição sobre cadeias escolhida por Menuzzi foi proposta por Rizzi (1990), como parte dos critérios de identificação de uma cadeia: para que a relação entre duas posições $a$ e $b$ seja uma cadeia, não basta que haja co-indexação, c-comando e que não haja uma barreira entre $a$ e $b$; é preciso, também, que $a$ e $b$ satisfaçam a algum critério de "identidade" que, para Rizzi (1990), é o da "compatibilidade de especificações gramaticais":

COMPATIBILIDADE PARA CADEIAS [COMPCADEIA]

Se $(a, b)$ formam uma cadeia, então as especificações de traços de b devem ser compatíveis com as especificações de traços de a.

De acordo com a afirmação acima, só podem entrar numa relação de "cadeia" posições a e b que sejam compatíveis entre si com respeito à especificação de traços gramaticais - o que inclui $\mathrm{Caso}^{2}$, mas também número, gênero e pessoa.

configuração sintagmática da árvore que se adote - cf. Menuzzi (1999) para discussão.

2 Agradeço à observação da Profa. Dra. Cláudia Roberta Tavares Silva, que chamou a minha atenção para contextos do tipo:

(i) O João viu ele no espelho 
Para a análise das relações entre $a$ gente e os pronomes de $1 \mathrm{ppl}$, Menuzzi observa que em $A$ gente $e_{i}$ já $\left\{\right.$ se $_{1} /$ *nos $\left._{i}\right\}$ viu na TV não há uma "barreira" entre a gente e nos: a relação anafórica satisfaz completamente o formato de uma cadeia e, portanto, as condições sobre cadeias atuam com máxima força, ou seja, COMPCADEIA é violada e a frase se torna inaceitável por haver incompatibilidade entre as duas posições da cadeia com respeito à pelo menos dois traços

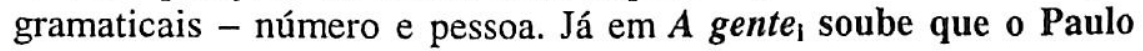
nos $_{\mathbf{i}}$ viu no Giovannetti ontem, a relação anafórica não é uma "cadeia" ótima, uma vez que cruza pelo menos uma barreira. Neste caso, de acordo com a hipótese de Menuzzi de que relações anafóricas são "cadeias analógicas", os efeitos de COMPCADEIA são menores - o grau de "violações" é atenuado -, e nos é completamente aceitável".

Em discussão sobre anafóricos do tipo SE (termo usado por Reinhart \& Reuland $(1991,1993)$ para formas pronominais como se/si em português e zich em holandês), Menuzzi (1999) formula a condição de VISIBILIDADE, que exige que anafóricos do tipo SE pertençam a uma cadeia-A. Nessa abordagem, os efeitos de LOCALIDADE são derivados das condições de localidade sobre cadeias, ou seja, quanto menos "local" é o contexto, maior o número de barreiras que se interpõem entre antecedente e forma anafórica, portanto, maior o número de violações de LOCALIDADE. A disponibilidade do anafórico $\mathrm{SE}$, então, diminui à medida que as violações de LOCALIDADE se acumulam. Se observarmos as alternâncias de formas anafóricas que são encontradas na anáfora de $1 \mathrm{ppl}$ em PB - isto é, as escolhas anafóricas que a gente, em sua interpretação de $1 \mathrm{ppl}$, exigem em diferentes contextos sintáticos -, veremos que elas resultam da interação de três condições, todas

Onde, para alguns dialetos do $\mathrm{PB}$, pode haver leitura co-referente entre o antecedente e o pronome, mas, aparentemente, são atribuídos dois Casos distintos: um nominativo e outro, acusativo. Creio que esta possibilidade se configura em outro problema para os estudos das condições que atuam sobre cadeias, que não será contemplado neste artigo.

3 Menuzzi não deixa de reconhecer que falantes preferem a repetição da forma a gente, como em $A$ gente soube que o Paulo viu a gente no Giovannetti ontem, mas a frase em que nos é a forma anafórica não sofre nenhum prejuízo de gramaticalidade. 
independentemente motivadas: LOCALIDADE e COMPCADEIA, que atuam sobre o reflexivo de $3^{\mathrm{a}}$ pessoa, e COMPSEM, que atua sobre os pronomes de $1 \mathrm{ppl}$. Enquanto COMPSEM é uma condição "semântica", que controla a interface entre sintaxe e interpretação, a condição COMPCADEIA, é "gramatical", isto é, diz respeito exclusivamente à boa formação sintática de cadeias.

\section{O se reflexivo no dialeto alagoano}

Menuzzi desenvolve uma discussão sobre os padrões de escolhas anafóricas acionados pela expressão $a$ gente em sua interpretação de $1 \mathrm{ppl}$, partindo da evidência que eles sugerem que as violações de condições gramaticais e de condições semânticas devem ser comparadas a fim de que se possa determinar a boa formação de uma frase. Modelos gramaticais em que condições puramente gramaticais e semânticas não podem interagir entre si - por operarem em níveis de representação diferentes, por exemplo - não podem esclarecer as propriedades dos padrões anafóricos que ele discute. Assim ele deixa de fora modelos gramaticais gerativistas que assumem que 0 componente semântico simplesmente interpreta frases bem formadas do ponto de vista sintático, como o modelo padrão ou o modelo de regência e ligação.

Partindo das formulações de Menuzzi $(1999,2004)$ para observar o comportamento da anáfora reflexiva se no dialeto do PB falado em Alagoas, veremos que o se pode ser ligado, neste dialeto, a qualquer pronome sujeito:

(5) a) Eu já se vi na TV.

b) Tu já se viu na TV.

c) Você já se viu na TV.

d) Elelela já se viu na TV.

e) Nós já se vimos na TV.

f) A gente já se viu/vimos na TV.

g) Vocês já se viram na TV.

h) Eles/elas já se viram na TV.

É importante ressaltar que, à medida que a "distância" entre o pronome sujeito e o se reflexivo aumenta, a gramaticalidade das frases é prejudicada, e só um pronome com as mesmas especificações gramaticais do pronome sujeito torna as frases aceitáveis: 
(6) $* \mathrm{Eu}_{\mathrm{i}}$ acho que o Paulo já se $\mathrm{i}_{\mathrm{i}}$ viu na TV.

$\mathrm{Eu}_{\mathrm{i}}$ acho que o Paulo já $\mathrm{me}_{\mathrm{i}}$ viu na TV.

* $\mathrm{Tu}_{\mathrm{i}} /$ voce $_{\mathrm{i}}$ acha(s) que o Paulo já se $\mathrm{e}_{\mathrm{i}}$ viu na TV.

$\mathrm{Tu}_{\mathrm{i}} /$ você $_{\mathrm{i}}$ acha(s) que o Paulo já te $\mathrm{e}_{\mathrm{i}} / \mathrm{lhe}_{\mathrm{i}}$ viu na TV.

*Ele elela $_{\mathrm{i}}$ acha que o Paulo já se $\mathrm{e}_{\mathrm{i}}$ viu na TV.

Ele $_{\mathrm{i}} / \mathrm{ela}_{\mathrm{i}}$ acha que o Paulo já $\left(\mathrm{o}_{\mathrm{i}} / \mathrm{a}_{\mathrm{i}}\right)$ viu $\left(\right.$ ele $\left._{\mathrm{i}} / \mathrm{ela}_{\mathrm{i}}\right)$ na TV.

* Nós $s_{\mathrm{i}}$ achamos que o Paulo já se viu na TV

Nós ${ }_{i}$ achamos que o Paulo já nos $s_{i}$ viu na TV.

Nas frases marcadas pelo asterisco, a única interpretação possível para o se seria a de co-referência com Paulo, antecedente que se encontra no interior da sua categoria de regência. Segundo Reinhart \& Reuland (1991, 1993) apud Menuzzi (2004) - anafóricos SE adquirem traços- $\varphi$ por meio da relação de Spec-Head Agreement. Por isso, devem mover-se em Forma Lógica para INFL, onde entram na relação apropriada com o sujeito da oração. Como os efeitos de LOCALIDADE resultariam das limitações sobre este movimento, em algumas línguas, como o português, o reflexivo não pode ser "ligadoà-distância". Poderíamos formular para o se reflexivo do dialeto alagoano a generalização de que ele pode ser ligado a qualquer pronome pessoal na posição sujeito, mas só localmente. Esta generalização traz um problema para uma das noções básicas da Teoria da Regência e Ligação (Chomsky, 1981), apresentada abaixo:

(7) $\alpha$ is $X$-bound by $\beta$ if and only if $\alpha$ and $\beta$ are coindexed, $\beta$ ccommands $\alpha$, and $\beta$ is in an X-position.

Com base nessa generalização, perguntamo-nos: como é possível o se ser co-indexado ao seu antecedente em todas as frases dadas em (3), em que nem sempre há identidade de traços gramaticais? Mesmo as formulações de Menuzzi (1999, 2004), na seção anterior, não podem esclarecer a possibilidade de o $s e$ reflexivo poder ter qualquer pronome sujeito como antecedente, pois esta possibilidade também viola COMPCADEIA. Já em Lectures on Government and Binding, Chomsky (1981) observa que, apesar da exigência de que anáfora e antecedente compartilhem os traços 
apropriados, algumas línguas parecem empregar uma teoria de ligação diferente para certas anáforas:

For example, in Japanese, Korean and many other languages, the element translated as reflexive in English does not observe the binding theory sketched above, but rather can be linked to a subject that c-commands it. It has been argued that such elements (in some languages, at least) can be subject to pragmatic control, i.e., without antecedents. In other respects, these languages seem to have a binding theory in some ways similar to the one outlined here, though there are numerous open questions (...) (CHOMSKY 1981, p.229, nota 62).

De fato, os reflexivos do inglês apresentam uma especificação de traços gramaticais muito ampla, como podemos observar no quadro abaixo:

(8)

\begin{tabular}{|l|l|}
\hline Pessoa & Reflexivo \\
\hline I & myself \\
you & yourself \\
he & himself \\
it & herself \\
we & itself \\
you & ourselves \\
they & yourselves \\
\hline
\end{tabular}

No inglês, a especificação de traços gramaticais se dá não só em relação à pessoa e ao número, mas também em relação ao gênero (na terceira pessoa do singular), o que causa a agramaticalidade das sentenças abaixo, onde não há identidade de traços entre o reflexivo e o seu antecedente:

(9) *She cut himself

*Supporters of the president may blame himself

É interessante comparar o quadro em (8) com (10), apresentado a seguir, em que temos a relação entre a pessoa e a anáfora reflexiva para o PB, e (11) que é a tradução das frases em (9): 
(10)

\begin{tabular}{|l|l|}
\hline Pessoa & Reflexivo \\
\hline Eu & me \\
tu/você & te/se \\
ele/ela & se \\
nós/a gente & nos/se \\
vocês & se \\
eles/elas & se \\
\hline
\end{tabular}

(11) Ela se cortou.

Os aliados do presidente devem se culpar.

Já não há uma relação de um-para-um no paradigma apresentado em (10). O se, apesar da sua especificação de $3^{\text {a }}$ pessoa, pode ser a forma reflexiva para todas as outras. Como mostra a tradução de (9) em (11), o se absorve os traços de gênero e número do seu antecedente. Para o dialeto do PB falado em alagoas, poderíamos elaborar o quadro (12), abaixo:

(12)

\begin{tabular}{|l|l|}
\hline Pessoa & Anáfora reflexiva \\
\hline Eu & se \\
tu/você & se \\
ele/ela & se \\
nós/a gente & se \\
vocês & se \\
eles/elas & se \\
\hline
\end{tabular}

Já vimos que esta possibilidade de o se ter qualquer pronome sujeito como antecedente (no dialeto do PB falado em Alagoas) é restrita à condição deste pronome sujeito estar no mesmo domínio que o se, havendo entre os dois uma relação de c-comando. Especificamente nesse domínio, não parece ser necessária a concordância entre as especificações gramaticais do antecedente e da forma dependente, mas apenas quando esta é o se, como evidencia a agramaticalidade do exemplo abaixo:

(13) *Você $\hat{e}_{i}$ já te $e_{i}$ viu na TV. 


\section{Conclusão}

Como fica evidente, este artigo apresenta alguns pontos de partida para uma reflexão sobre o fenômeno apresentado que levam à problematização de alguns instrumentos de análise oferecidos pela teoria adotada e que representam um desafio para a pesquisa. A relevância de outros aspectos, como a estrutura interna dos pronomes, a importância da seleção argumental do verbo nessas estruturas, o enfraquecimento da concordância em $\mathrm{PB}$, assim como os refinamentos propostos por modelos mais recentes, como o Programa Minimalista, não são ignorados e serão explorados numa próxima etapa do trabalho investigativo.

\section{Referências}

CHOMSKY, N. Lectures on Government and Binding. Dordrecht: Foris Publications, 1981.

MENUZZI, S. Binding Theory and Pronominal Anaphora in Brazilian Portuguese. Holland Academic Graphics, Haia (Série "LOT Dissertations"), 1999.

MENUZZI, S. First Person Plural Anaphora in Brazilian Portuguese. In: COSTA, J. (ed.). Portuguese Syntax: New Comparative Studies. New York: Oxford University Press, 2000.

MENUZZI, S. Concordância na Anáfora Pronominal. In: Sentido e significação: em torno da obra de Rodolfo Ilari. São Paulo: Contexto, 2004.

REINHART \& REULAND, Tanya \& Eric. Anaphors and Logophors: an Argument Structure Perspective. In REULAND, E. \& KOSTER, J. (eds.). Long-Distance Binding, 283-321. Cambridge University Press, 1991.

REINHART \& REULAND, Tanya \& Eric. Reflexivity. Linguistic Inquiry 24, 657-720, 1993.

RIZZI, Luigi. Relativized Minimality. MIT Press, Cambridge (EUA), 1990. 